\title{
Segmented copolymers with poly(ester amide) units of uniform length: synthesis
}

\author{
R. J. Gaymans* and J. L. de Haan \\ University of Twente, Department of Chemical Technology, PO Box 217, 7500 AE, The \\ Netherlands \\ (Received 17 July 1992; revised 11 January 1993)
}

\begin{abstract}
Segmented copolymers were synthesized from poly(tetramethylene oxide) with hydroxy end-groups or aliphatic diols and a short-chain diester diamide with a uniform length. The diester diamide ( $N, N^{\prime}$-bis( $p$-carbomethoxybenzoyl)butanediamine) $\left(T_{\mathrm{m}}=257^{\circ} \mathrm{C}\right)$ used is made from butanediamine and an excess of dimethyl terephthalate. The polymers are prepared in the melt with $\mathrm{Ti}\left(\mathrm{OCH}_{3} \mathrm{H}_{7}\right)_{4}$ as catalyst, for $30 \mathrm{~min}$ at $160-170^{\circ} \mathrm{C}$ under atmospheric pressure and $60 \mathrm{~min}$ at $250-260^{\circ} \mathrm{C}$ under a high vacuum. The polymers were studied by solution viscometry, differential scanning calorimetry and dynamic mechanical thermal analysis. The melting and glass transition temperatures decreased with increasing soft-block length. The crystalline order of the uniform unit is high and not very dependent on the soft-block length. The rate of crystallization is very fast. The moduli of these polymers are hardly dependent on temperature in the region between $T_{\mathrm{g}}$ and $T_{\mathrm{m}}$.
\end{abstract}

(Keywords: segmented copolymers; poly(tetramethylene oxide); uniform unit length; poly(ester amide); butanediamine; dimethyl terephthalate)

\section{INTRODUCTION}

Segmented block copolymers have been known for quite some time ${ }^{1-7}$. With segmented block copolymers at least two types of blocks are used. If one of the blocks separates by crystallization, the system has at least one glass transition temperature and a melting temperature. In these block copolymers the chemical structure of the amorphous phase is different from that of the crystalline phase. For that reason the $2 / 3$ rule for $T_{\mathrm{g}} / T_{\mathrm{m}}$ of homopolymers is not applicable to segmented block copolymers. The $T_{\mathrm{g}} / T_{\mathrm{m}}$ ratio can be influenced by choosing the type and length of the segments. Most studied are segmented block copolymers with a low $T_{\mathrm{g}}$ $\left(-50^{\circ} \mathrm{C}\right)$ and a high melting temperature $\left(\sim 200^{\circ} \mathrm{C}\right)$. For the crystallizable blocks, poly(butylene terephthalate) (PBT), polyamides and polyurethanes are used; and for the low- $T_{\mathrm{g}}$ blocks, polyethers, aliphatic polyesters and polyolefins ${ }^{1-7}$. The crystalline phase forms the physical crosslinks and a fast crystallization of this phase makes easy melt processing possible. High chain order of the crystallizable phase is thus important both for the rate of crystallization as well as for the network structure of the system.

A well studied system is the block copolymer of poly(butylene terephthalate) and poly(tetramethylene oxide) (PBT- $b$-PTMO) ${ }^{1,3,6,7}$. The melting temperature of this system is around $200^{\circ} \mathrm{C}$ and the glass transition temperature around $-45^{\circ} \mathrm{C}$. In order to have a high rate of crystallization and a stable crystalline structure, the length of the PBT segments must on average be at least four repeat units ${ }^{3,6}$. In addition to the drop in modulus at the glass transition, there is a considerable drop in

* To whom correspondence should be addressed 0032-3861/93/204360-05

(C) 1993 Butterworth-Heinemann Ltd. modulus in the $T_{\mathrm{g}}-T_{\mathrm{m}}$ region ${ }^{6}$. A similar drop in modulus above the glass transition is observed in semicrystalline homopolymers.

A considerably smaller drop in modulus with temperature in the region above $T_{\mathrm{g}}$ is observed in segmented polyurethane block copolymers with uniform urethane block length ${ }^{8-11}$. Additionally, these materials have a better microphase separation, a higher modulus and higher elongation at break. Here, too, the melting temperature decreases with decreasing block length, and very short blocks with only two urethane groups have difficulty in phase-separating ${ }^{10,11}$. If these materials are melt-processed, the uniform block length behaviour is lost due to urethane interchange reactions ${ }^{10,11}$. Segmented polymers containing PTMO soft blocks, which phase-separate easily, are produced from polyamides with a high order, e.g. polyamide- $4,6^{12}$.

So if a high order of the crystallizable units can be combined with a uniform length, a good phase separation can be accomplished with interesting properties of the copolymer. A polymer with a very high order and a high melting temperature is polyamide-4,T(PA4T) $\left(\Delta H_{\mathrm{m}}=108 \mathrm{~J} \mathrm{~g}^{-1}, T_{\mathrm{m}}=425 / 475^{\circ} \mathrm{C}\right)^{13}$. A short uniform block of PA4T will still have a high order and a high melting temperature (but lower than the polymer). The diamide T4T (1.5 repeat units of PA4T) has a melting temperature of $180^{\circ} \mathrm{C}^{14}$. The diamide diester $\mathrm{T} 4 \mathrm{~T}$.dimethyl has a melting temperature of $255-256^{\circ} \mathrm{C}^{15}$.

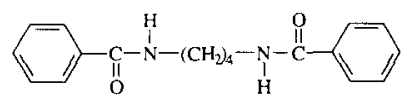

T4T

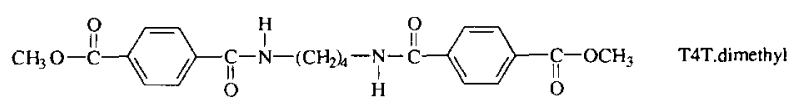


Polymers have been studied with T6T groups (1.5 repeat units of PA6T), e.g. T6T-hexanediol ${ }^{16-19}$ and segmented block copolymers T6T-hexanediol- $b$ PTMO $^{20,21}$. With PTMO of molecular weight 1000 $\left(\mathrm{PTMO}_{1000}\right)$ the melting temperature and the order of the copolymer decrease gradually with $\mathrm{T} 6 \mathrm{~T}$-hexanediol unit length. With a block length of 1 , just T6T units, the melting temperature is $111^{\circ} \mathrm{C}$ and $\Delta H_{\mathrm{m}}=24 \mathrm{~J} \mathrm{~g}^{-1}$ (ref. 20).

The strictly alternating polymers, e.g. T6T-hexanediol (6NT6), can be regarded as homopolymers ${ }^{16-19}$. These strictly alternating polymers have a high order and have engineering plastic behaviour. Similar poly(ester amide)s have been studied by Aharoni, who found that these materials can have liquid-crystalline behaviour ${ }^{22}$.

We chose for crystallizable segments, T4T units, and for the soft segments, PTMO. The synthesis of T4T-PTMO and the influence of the unit length of the PTMO segment on the properties have been studied.

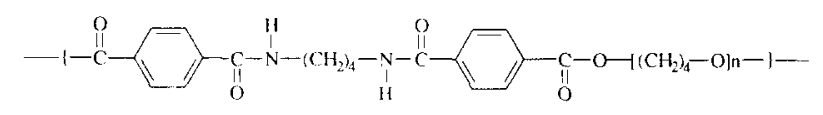

T4T-PTMO

\section{EXPERIMENTAL}

\section{Materials}

Dimethyl terephthalate (DMT), 1,4-butanediamine (BDA), 1,6-hexanediol (HDO) and 1,8-octanediol were obtained from Merck. Hydroxy-terminated PTMO was obtained from BASF. BDA was distilled prior to use. Methanol was treated with magnesium and iodine prior to distillation. Toluene was dried with lithium aluminium hydride prior to distillation. The catalyst was a solution of $1.48 \mathrm{~g}$ tetraisopropyltitanate $\mathrm{Ti}\left(\mathrm{OC}_{3} \mathrm{H}_{7}\right)_{4}$ and $0.1 \mathrm{~g}$ sodium in $30 \mathrm{ml}$ of distilled $\mathrm{n}$-butanol.

\section{Synthesis}

$\mathrm{N}, \mathrm{N}^{\prime}$-bis(p-carbomethoxybenzoyl)butanediamine (T4T.dimethyl). First, $111 \mathrm{~g}(0.6 \mathrm{~mol})$ DMT, $5 \mathrm{~g}(0.06 \mathrm{~mol})$ BDA, $395 \mathrm{ml}$ anhydrous toluene, $106 \mathrm{ml}$ anhydrous methanol and $10 \mathrm{ml} \mathrm{Li}\left(\mathrm{OCH}_{3}\right)(1.89 \mathrm{M}$ in methanol) were mixed in a flask with a stirrer, condenser and nitrogen inlet. The flask was heated to reflux for $40 \mathrm{~h}$. During this time the reaction product precipitated. The precipitate was separated by hot filtration, washed twice with hot toluene and once with hot methanol, and was subsequently dried $\left(24 \mathrm{~h}\right.$ at $\left.100^{\circ} \mathrm{C}\right)$.

T4T-PTMO copolymer. The reactions were carried out in a 1.3 litre oil-heated stainless-steel Juvo reactor with a nitrogen inlet and mechanical stirrer. A typical example of a synthesis of poly(ester amide)-PTMO copolymers is given below with $\mathrm{PTMO}_{1000}$. First, $400 \mathrm{~g}$ of $\mathrm{PTMO}_{1000}(0.40 \mathrm{~mol}), 165 \mathrm{~g}$ of T4T.dimethyl $(0.40 \mathrm{~mol})$ and $4 \mathrm{ml}$ catalyst solution was heated to $170^{\circ} \mathrm{C}$ and kept for $30 \mathrm{~min}$ at that temperature. Then the temperature was raised to $260^{\circ} \mathrm{C}$ and vacuum applied for $30 \mathrm{~min}$ at $10-15 \mathrm{mmHg}$ and subsequently $60 \mathrm{~min}$ at $0.1-0.01 \mathrm{mmHg}$. After this the reaction mass was allowed to cool. The polymers so obtained were white.

T4T-hexanediol/octanediol. The reactions were carried out in a $250 \mathrm{ml}$ glass vessel with a nitrogen inlet and mechanical stirrer. To the reactor was added $1.44 \mathrm{~g}$ hexanediol (12.2 mmol), $1.81 \mathrm{~g}$ octanediol $(12.2 \mathrm{mmol})$, $10.0 \mathrm{~g}$ T4T.dimethyl (=24.3 mmol), $3 \mathrm{ml}$ ethylene glycol (solvent) and $0.25 \mathrm{ml}$ catalyst solution. The reaction mass was heated to $160^{\circ} \mathrm{C}$ and kept at that temperature for $30 \mathrm{~min}$. Then the temperature was raised to $250^{\circ} \mathrm{C}$ and vacuum applied for $10 \mathrm{~min}$ at $10 \mathrm{mmHg}$ and for $60 \mathrm{~min}$ at $0.5-0.05 \mathrm{mmHg}$.

\section{Characterization}

Viscometry. The $\eta_{\mathrm{inh}}$ of the polymers was measured at $25^{\circ} \mathrm{C}$ using a $0.25 \%$ solution in $\mathrm{PhOH} / \mathrm{C}_{2} \mathrm{Cl}_{4} \mathrm{H}_{2}$ $(50 / 50 \mathrm{~mol} \%)$.

Thermal analysis. For the differential scanning calorimetry (d.s.c.), a Perkin-Elmer DSC-7 instrument was used with a heating and cooling rate of $20^{\circ} \mathrm{C} \mathrm{min}^{-1}$. The melt-pressed samples were first heated to $20^{\circ} \mathrm{C}$ above their melting temperatures, equilibrated for $5 \mathrm{~min}$, cooled and heated again. The area under the second melting curve was used for the measurement of the heat of fusion; the peak maximum was taken as the melting temperature.

Dynamic mechanical thermal analysis. With a Myrenne (ATM 3) torsion pendulum instrument, the torsion moduli $G^{\prime}$ and $G^{\prime \prime}$ were analysed at a constant frequency of $1 \mathrm{~Hz}$ and a heating rate of $1.8^{\circ} \mathrm{C} \mathrm{min}^{-1}$. For the $T_{\mathrm{g}}$, the $G_{\max }^{\prime \prime}$ was taken.

Melt processing. Plaques were made by compression moulding. Therefore, the dried material was heated in the press to at least $20^{\circ} \mathrm{C}$ above the melting temperature, equilibrated for $5 \mathrm{~min}$ and cooled at an approximate rate of $20^{\circ} \mathrm{C} \mathrm{min} \mathrm{m}^{-1}$.

\section{RESULTS AND DISCUSSION}

\section{Synthesis}

The object is to study segmented copolymers with T4T crystallizable units and which are linked with amorphous segments.

For the synthesis, the polyester condensation method was followed, using T4T.dimethyl and a dihydroxy oligomer as starting materials.

The T4T.dimethyl was obtained in the same way as T6T.dimethyl ${ }^{23}$. Tetramethylenediamine and a large excess of DMT were reacted in a methanol/toluene mixture at reflux temperature. Soon a suspension was formed of the monoamide, which was slowly converted to the T4T.dimethyl. With i.r. spectroscopy, the formation of amide groups could be observed. In T4T.dimethyl the amide carbonyl band at $1620 \mathrm{~cm}^{-1}$ was as strong as the ester carbonyl band $\left(1715 \mathrm{~cm}^{-1}\right)$ (Figure l).

The T4T.dimethyl has a melting point of $257^{\circ} \mathrm{C}$ and a heat of fusion of $144 \mathrm{~J} \mathrm{~g}^{-1}$. The melting point corresponds to the melting point found by Williams et $a l^{15}$.

The synthesis of the segmented polymers with T4T.dimethyl and PTMO was carried out in the bulk. The reaction mixture at the polymerization temperature seems to be homogeneous. The step in PTMO block length between 250 and 650 is large, and therefore a 50/50 mixture was prepared (average molecular weight 450 ). The polymers obtained were all white and of high molecular weight (Table 1).

T4T-hexanediol/octanediol copolymers were prepared with the aim to have a very short average unit length of the soft segment and with a low order of that segment. 


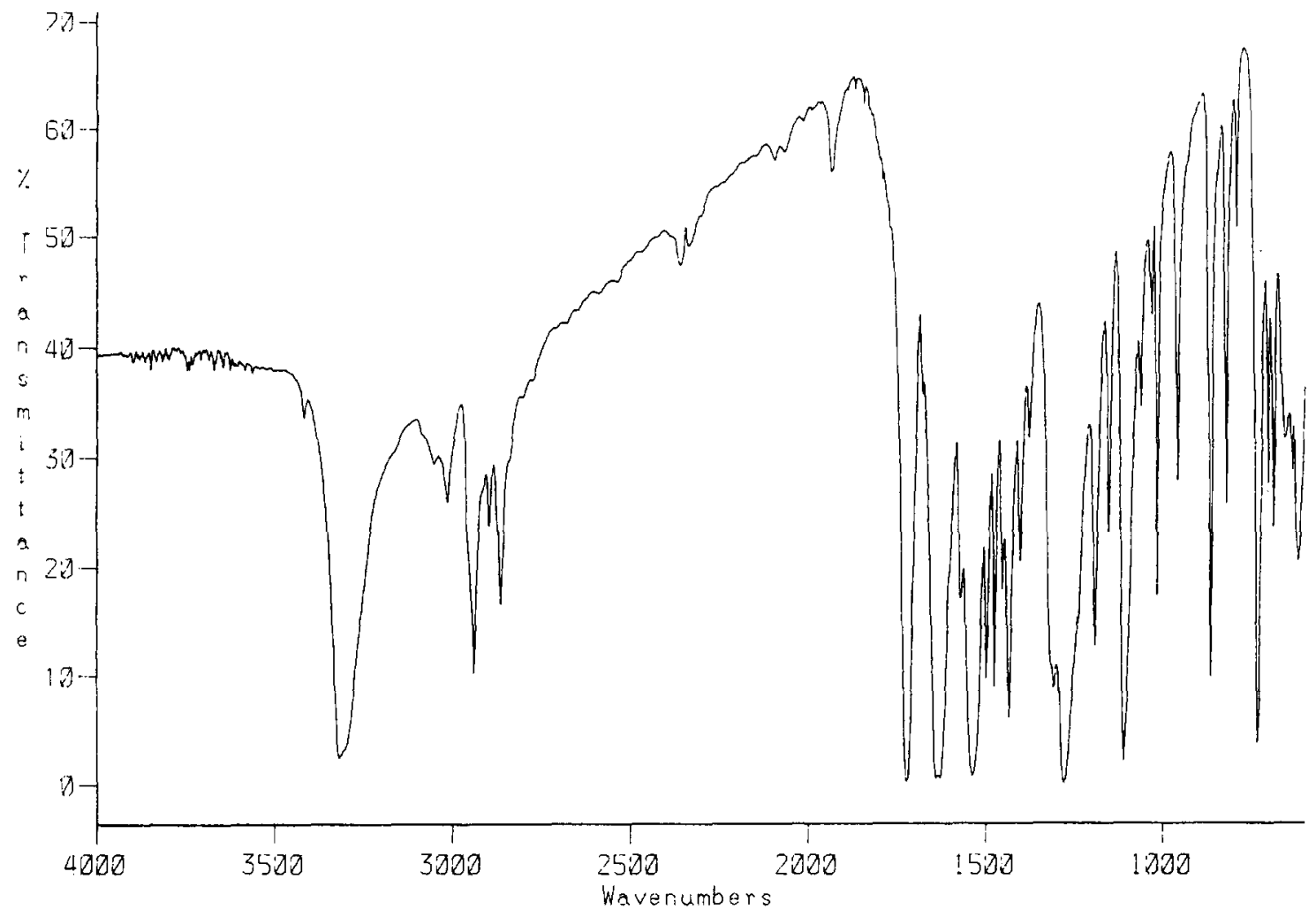

Figure 1 I.r. spectrum of T4T.dimethyl

Table 1 The T4T-PTMO data

\begin{tabular}{|c|c|c|c|c|c|c|c|c|c|c|}
\hline T4T polymer & $\begin{array}{l}\text { Mol. wt, } \\
\text { soft }^{a}\end{array}$ & $w_{\mathrm{T} 4 \mathrm{~T}}^{b}$ & $\begin{array}{l}\eta_{\text {inh }} \\
\left(\mathrm{dl} \mathrm{g}^{-1}\right)\end{array}$ & $\begin{array}{l}T_{\mathrm{m}} \\
\left({ }^{\circ} \mathrm{C}\right)\end{array}$ & $\begin{array}{l}T_{\mathrm{m}}-T_{\mathrm{c}} \\
\left({ }^{\circ} \mathrm{C}\right)\end{array}$ & $\underset{\left(\mathrm{Jg}^{-1}\right)}{\Delta H_{\mathrm{m}}}$ & $\begin{array}{l}\Delta H_{\mathrm{m}} \\
(\mathrm{J} / \mathrm{g} \mathrm{T} 4 \mathrm{~T})\end{array}$ & $\begin{array}{l}T_{\mathrm{g}} \\
\left({ }^{\circ} \mathrm{C}\right)\end{array}$ & $\begin{array}{l}G_{25}^{\prime} \\
(\mathrm{MPa})\end{array}$ & $T_{\mathrm{g}} / T_{\mathrm{m}}$ \\
\hline $\begin{array}{l}\text { Hexanediol/octanediol } \\
(50 / 50)\end{array}$ & 98 & 0.796 & 0.49 & 229 & 32 & 76 & 95 & 103 & 1000 & 0.75 \\
\hline $\mathrm{PTMO}_{250}$ & 250 & 0.604 & 1.33 & 185 & 9 & 36 & 56 & $43(-79)$ & 754 & 0.69 \\
\hline $\begin{array}{l}\mathrm{PTMO}_{250 / 650} \\
(50 / 50)\end{array}$ & 450 & 0.459 & - & 173 & 7 & 39 & 76 & -50 & 210 & 0.50 \\
\hline $\mathrm{PTMO}_{650}$ & 650 & 0.370 & 1.39 & 179 & 19 & 28 & 73 & -58 & 117 & 0.48 \\
\hline $\mathrm{PTMO}_{1000}$ & 1000 & 0.276 & 1.18 & 153 & 16 & 27 & 95 & -65 & 65 & 0.49 \\
\hline $\mathrm{PTMO}_{2000}$ & 2000 & 0.160 & 1.49 & 133 & 11 & 16 & 98 & $-70(-5)$ & 18 & 0.50 \\
\hline $\mathrm{PTMO}_{2900}$ & 2900 & 0.116 & 0.85 & 84 & - & 9 & 76 & $-73(-5)$ & 13 & 0.56 \\
\hline
\end{tabular}

${ }^{a}$ Soft segment without hydroxyl groups

${ }^{b} \mathrm{~T} 4 \mathrm{~T}$ unit including the ester groups

The synthesis of the polymer with hexanediol/octanediol and T4T.dimethyl could best be carried out with a solvent, and ethylene glycol was used. It is expected that virtually all the ethylene glycol will be removed in the high-vacuum polymerization step, as in the case of excess of diols the more highly volatile diol is always stripped off. Even if a small part did remain, that would not limit the degree of polymerization and increase the disorder of the amorphous segment. The molecular weight of the polymer could further be increased by a solid-state postcondensation under nitrogen $\left(24 \mathrm{~h}, 150^{\circ} \mathrm{C}\right)$.

\section{Differential scanning calorimetry}

The segmented polymers so obtained have all T4T segments and PTMO or hexanediol/octanediol segments. The T4T units are very short, with two amide groups, and uniform in length. Including the ester atoms the molecular weight of the T4T unit is 382 . The weight fraction of T4T units $\left(w_{\mathrm{T} 4 \mathrm{~T}}\right)$ in the polymers was calculated.

In Table 1 the melting temperatures, crystallization temperatures and the heats of fusion of the polymers are given. The melting and crystallization temperatures decrease with increasing soft-segment length. The hexanediol/octanediol segmented copolymers have a melting temperature of $229^{\circ} \mathrm{C}$ and T4T-PTMO ${ }_{2900}$ has a melting temperature of $83^{\circ} \mathrm{C}$. The strong decrease in melting temperature with increasing soft-unit length is surprising. It is known from the literature that for PBT- $b$-PTMO and T6T-hexanediol- $b$-PTMO segmented block copolymers the melting temperature is dependent on the average length of the hard block but little on the soft-block length (hard-block content) (3, $^{3,20,24}$. The hardblock length in segmented block copolymers influences the lamellar thickness and with that the melting temperature ${ }^{3,6}$. In the T4T copolymers it is expected that, 
as the hard-unit length is constant, the lamellar thickness is constant. The change in melting temperature must then be explained differently than for the PBT- $b$-PTMO systems.

The melting temperature seems to be linearly dependent on the T4T concentration (Figure 2). A more detailed structure analysis of our systems will be presented in a second article 25

The difference between the melting and crystallization temperatures is the undercooling before crystallization. The lower this value, the higher is the crystallization rate of the system. The fast crystallizing PBT homopolymer has, with a d.s.c. scan at $20^{\circ} \mathrm{C} \mathrm{min}^{-1}$ heating and cooling, a $T_{\mathrm{m}}-T_{\mathrm{c}}$ of $32^{\circ} \mathrm{C}$; PBT- $b$-PTMO segmented block copolymers have a value of $35-45^{\circ} \mathrm{C}^{24}$. The $T_{\mathrm{m}}-T_{\mathrm{c}}$ for the hexanediol/octanediol segmented copolymer is $32^{\circ} \mathrm{C}$, and for the others between 7 and $20^{\circ} \mathrm{C}$ (Table l). These extremely low values suggest a very fast crystallization for a copolymer and faster than PBT homopolymer and PBT- $b$-PTMO segmented block copolymers. The uniform unit length of the T4T unit must be the reason for this.

The heats of fusion decrease with increasing softblock length. If it is assumed that what is melting at $T_{\mathrm{m}}$ is only the T4T unit, then the heats of fusion based on the T4T unit can be calculated. These values range from $95 \mathrm{~J} \mathrm{~g}^{-1}$ for hexanediol/octanediol to $76 \mathrm{~J} \mathrm{~g}^{-1}$ for PBT- $b$-PTMO ${ }_{2900}$ with some scatter for the PTMOs in between. This suggests that, independent of soft-segment block length, the crystalline order of the T4T units is high.

\section{Dynamic mechanical thermal analysis}

The torsional behaviour of melt-pressed strips was studied. The $T_{\mathrm{g}}$ of the hexanediol/octanediol system was $103^{\circ} \mathrm{C}$, for $\mathrm{PTMO}_{250}$ at $43^{\circ} \mathrm{C}$ and for the longer PTMOs below $-55^{\circ} \mathrm{C}$ (Table l, Figures 2 and 3). The $T_{\mathrm{g}}$ is below room temperature with PTMO block molecular weight higher than 450 , and rises very rapidly with smaller block length (increasing hard-block content).

With a short soft-unit length the $T_{\mathrm{g}}$ of the material is above room temperature and the $T_{\mathrm{g}} / T_{\mathrm{m}}$ ratio is above $2 / 3$. These systems have engineering plastic characteristics. With longer soft-block length the $T_{\mathrm{g}}$ values are well below room temperature, the $T_{\mathrm{g}} / T_{\mathrm{m}}$ ratio is of the order of 0.50 and the crystallization is very

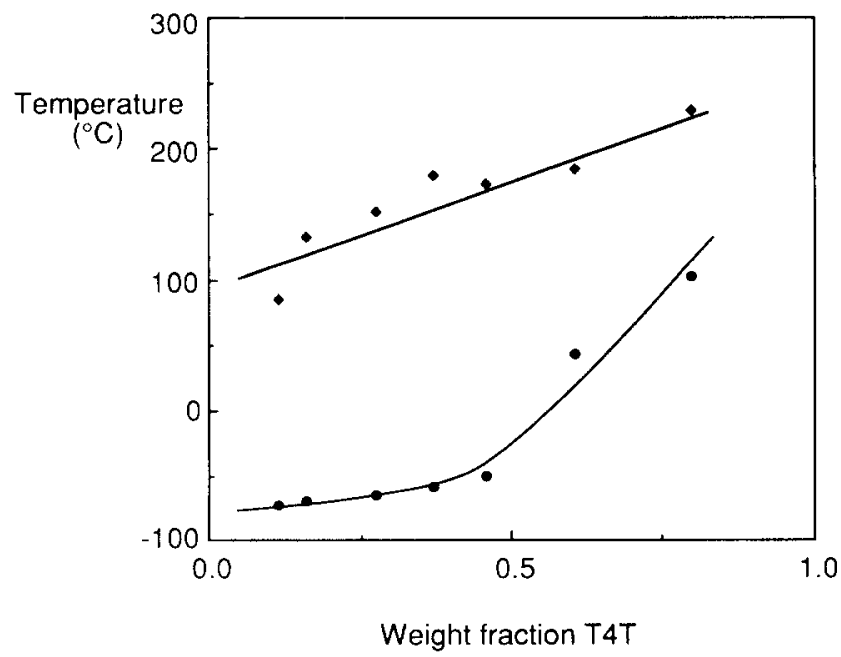

Figure $2 T_{\mathrm{m}}(\bullet)$ and $T_{\mathrm{g}}(\bullet)$ as functions of the weight fraction of 'T $4 \mathrm{~T}$ units $\left(w_{\mathrm{T} 4 \mathrm{~T}}\right)$

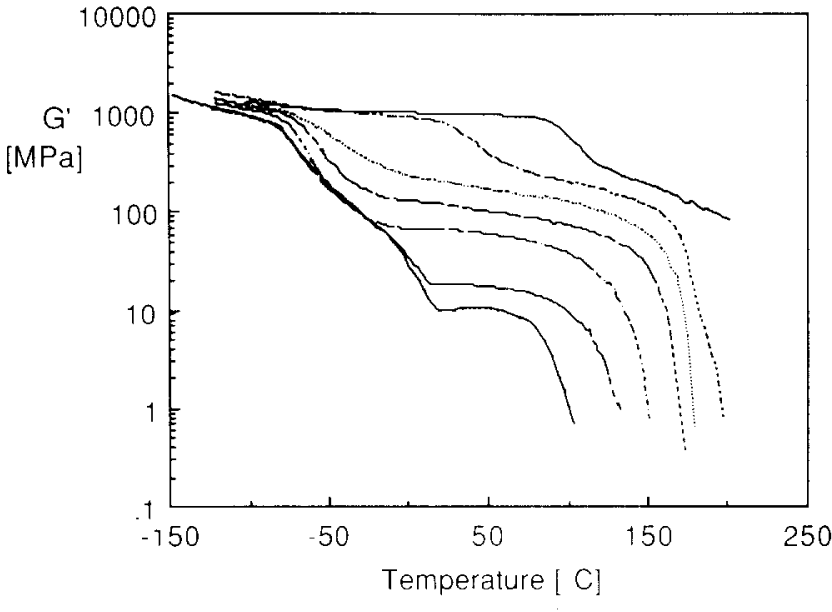

Figure 3 Torsion modulus $G^{\prime}$ vs. temperature (from top): (-.....) hexanediol/octanediol; ( - . - -) PTMO PT50 $_{25} ;(\cdots)$ PTMO $_{250650} ;(-\ldots)$ PTMO $_{650} ;(\ldots \ldots)$ PTMO $_{1000} ;(\ldots-)$ PTMO $_{2000} ;(\ldots)$ $\mathrm{PTMO}_{2900}$

fast. These materials have interesting thermoplastic elastomeric behaviour. The torsion modulus at room temperature decreases about two decades with increasing soft-block length.

It can also be seen that there is a relatively small change in modulus in the temperature range between $T_{\mathrm{g}}$ and $T_{\mathrm{m}}$. This suggests that with the uniform length of the poly(ester amide) units the crystalline stability is high and this is in agreement with the results on polyurethanes ${ }^{10.11}$. As these d.m.t.a. measurements are on melt-processed strips, it clearly indicates that after melt processing the uniform unit length behaviour is still present.

\section{CONCLUSIONS}

Segmented copolymers with T4T units crystallize very fast and have a high stability of the crystalline phase. Depending on the length and structure of the amorphous segment, the glass transition can be varied between -70 and $100^{\circ} \mathrm{C}$. The length of the amorphous segment influences strongly the melting temperature of the system; the crystallinity of the T4T unit is only slightly influenced. These segmented copolymers with uniform length seem to be melt-processable without losing their uniform length behaviour.

\section{REFERENCES}

1 Schroeder, H. E. and Cella, R. J. in 'Encyclopedia of Polymer Science and Engineering, Vol. 12, 2nd Edn., Wiley, London, 1988 , p. 75

2 Meckel, W., Goyert, W. and Wieder, W. in 'Thermoplastic Elastomers' (Eds. N. R. Legge, G. Holden and H. E. Schroeder), Hanser, Munich, 1987, Ch. 2

3 Adams, R. K. and Hoeschele, G. K. in 'Thermoplastic Elastomers' (Eds. N. R. Legge, G. Holden and H. E. Schroeder), Hanser, Munich, 1987, Ch. 8

4 Nelb, R. G., Chen, A. T. and Onder, K. in "Thermoplastic Elastomers' (Eds. N. R. Legge, G. Holden and H. E. Schroeder), Hanser, Munich, 1987, Ch. 9A

5 Deleens, G. in 'Thermoplastic Elastomers' (Eds. N. R. Legge, G. Holden and H. E. Schroeder), Hanser, Munich, 1987, Ch. 9B

6 Wegner, G. in 'Thermoplastic Elastomers' (Eds. N. R. Legge, G. Holden and H. E. Schroeder), Hanser, Munich, 1987, Ch. 12.5

7 van Berkel, R. W. M., de Graaf, S. A. G., Huntjes, F. J. and Vrouwenreats, C. M. F. in 'Developments in Block Copolymers', Vol. 1 (Ed. I. Goodman), Applied Science, London, 1982, Ch. 7 
8 Harrell, L. L. Macromolecules 1969, 2, 607

9 Ng, H. N., Allegrezza, A. E., Seymour, R. W. and Cooper, S. L. Polymer 1973, 14, 255

10 Miller, J. A., Lin, S. B., Hwang, K. K. S., Wu, K. S., Gibson, P. E. and Cooper, S. L. Macromolecules 1985, 18, 32

11 Eisenbach, C. D., Baumgartner, M. and Günter, C. in 'Advances in Elastomers and Rubber Elasticity' (Eds. J. Lal and J. E. Mark), Plenum, New York, 1987, p. 51

12 Gaymans, R. J., Schwering, P. and de Haan, J. L. Polymer 1989, 30, 974

13 Gaymans, R. J. J. Polym. Sci., Polym. Chem. Edn. 1985, 23, 1599

14 Gaymans, R. J. J. Polym. Sci., Polym. Phys. Edn 1977, 15, 587

15 Williams, J. L. R., Laasko, T. M., Dunham, K. R., Borden, D. G., van den Berghe, J., van Allan, J. A. and Reynolds, D. D. J. Org. Chem. 1960, 25, 817
16 Castaldo, L., De Candia, F., Maglio, G., Palumbo, R. and Strazza, G. J. Appl. Polym. Sci. 1982, 27, 1809

17 Williams, J. L. R., Laakso, T. M. and Contois, L. E. J. Polym. Sci. 1962, 61, 353

18 Cesari, M., Perego, G. and Melis, A. Eur. Polym. J. 1976, 12, 585

19 Conte, G. and D'llario, L. Polymer 1979, 20, 559

20 Sorta, E. and della Fortuna, G. Polymer 1980, 21, 728

21 Cernia, E. and D'llario, L. J. Polym. Sci., Polym. Phys. Edn 1985, 23, 49

22 Aharoni, S. M. Macromolecules 1988, 21, 1941

23 Manzini, G., Creszanzi, V., Ciana, A., della Fortuna, G. and Zotteri, L. Eur. Polym. J. 1973, 27, 515

24 Manuel, H. J. and Gaymans, R. J. Polymer 1993, 34, 636

25 van Hutten, P. F., Mangnus, R. M., de Haan, J. L. and Gaymans, R. J. Polymer in press 